\title{
A screening of resistance to sweet potato weevil (Cylas formicarius Fab.) in a collection of sweet potato clones under laboratory conditions
}

\author{
YOSEP S. MAU ${ }^{1,2, \vartheta}$, MARGERITA N. WADU ${ }^{1}$, ANTONIUS S.S. NDIWA ${ }^{1}$, JENNY E.R. MARKUS ${ }^{1}$, \\ I G.B. ADWITA ARSA ${ }^{1}$ \\ ${ }^{1}$ Department of Agrotechnology, Faculty of Agriculture, Universitas Nusa Cendana. Jl. Adisucipto, Penfui, Kupang 85001, East Nusa Tenggara, \\ Indonesia. `email: yosepmau@yahoo.com \\ ${ }^{2}$ Archipelagic Dryland Center of Excellence (PUI Lahan Kering Kepulauan), Universitas Nusa Cendana. J1. Adisucipto, Penfui, Kupang 85001, East \\ Nusa Tenggara, Indonesia
}

Manuscript received: 21 August 2021. Revision accepted: 25 September 2021.

\begin{abstract}
Mau YS, Wadu MN, Ndiwa ASS, Markus JER, Arsa IGBA. 2021. A screening of resistance to sweet potato weevil (Cylas formicarius Fab.) in a collection of sweet potato clones under laboratory conditions. Intl J Trop Drylands 5: 41-47. Sweet potato is a potential carbohydrate source as a rice substitute in Indonesia, especially in East Nusa Tenggara (ENT). However, the productivity of this crop is still low at the farmer level due to, among others, the use of low-yielding varieties and yield loss caused by sweet potato weevil (SPW), Cylas formicarius. The use of SPW resistant varieties is considered the most effective and eco-friendly way of controlling the pest. However, the availability of resistant varieties is currently limited. This study aimed to evaluate the SPW-induced damage intensity and SPW-resistance level in a collection of sweet potato clones. The study was conducted in the laboratory of Universitas Nusa Cendana, Kupang, Indonesia. Observed variables included the percentage of damaged roots, the intensity of root damage, the number of $C$. formicarius per root, the number of feeding tunnels per root, root epidermal thickness, and root latex level. Observed data were subjected to analysis of variance followed by Duncan's post hoc test of 5\%, except root latex level that was subjected to descriptive analysis. A correlation analysis was also performed. The damaged root percentage ranged from $77.8 \%$ to $100 \%$, and the intensity of root damage was from $14.0 \%$ to $76.6 \%$. The laboratory assay categorized the tested genotypes into Moderately Resistant, Moderately Susceptible, and Susceptible levels, with the Resistant category being absent. The SPWs ranged from 1.4 to 31.9 per root, while the number of feeding tunnels ranged from 1.4 to 31.1 per root. The observed sweet potato genotypes possessed root epidermal thickness between $1 \mathrm{~mm}$ to $4 \mathrm{~mm}$, and the root latex was low to a high level. The study revealed a strong correlation between the damaged root intensity and the number of feeding tunnels per root or SPWs per root. A highly positive correlation was also observed between the number of SPWs and the number of feeding tunnels per root. A weak and positive correlation was found between root epidermal thickness and the number of SPWs or feeding tunnels per root.
\end{abstract}

Keywords: Cylas formicarius, resistance, sweet potato hybrid, sweet potato weevil

\section{INTRODUCTION}

Crop production and productivity are affected by factors such as the genetic potentials of the crop, environment (growing) condition, and biotic factors. In addition, the agronomical practices applied also play an essential role in crop productivity. Suboptimal conditions of at least one of these factors may lead to low crop production and productivity. In practice, more than one of these factors may occur altogether in suboptimal conditions. Thus, managing a crop cultivar to produce genetic potential is a challenging task. Therefore, driving all these factors close to their optimal conditions is necessary for maximum crop productivity.

Pests and diseases are generally considered as biotic factors hampering crop production. In sweet potato (Ipomoea batatas L. (Lam)), sweet potato weevil/SPW (Cylas formicarius (Fab.)) is known as the most devastating pest of the crop (Talekar 1982; Chalfant et al. 1990; Smith and Beuzelin 2015; Chen 2017) as its infestation directly implicates in high storage root damage intensity, and hence, high storage root yield loss is inevitable (Jansson et al. 1987; Alcazar et al. 1997; Nderitu et al. 2009).

Chemical control is the most popular way of controlling the SPW (Smith and Beuzelin 2015; Chen 2017), but this method is considered not environmentally safe. Thus, reducing the use of chemical pesticides and promoting more ecologically safe control measures are strongly encouraged. In addition, the use of chemical control strategy is also sometimes ineffective because the weevils are subterranean and spend most of their life cycles inside the roots (Anyanga 2015). Thus, the use of resistant varieties is considered an efficient and more environmentally friendly control method of SPW. Furthermore, resistant varieties are also more appropriate for the subsistent sweet potato farmers as they lack the chemical control strategy (Chen 2017). Nonetheless, SPW resistant varieties are hardly available (Mao et al. 2001; Mau et al. 2011).

Sweet potato is the second most important root crop in East Nusa Tenggara (ENT) Province, Indonesia, after cassava (BPS NTT 2020). It has been used as a substitute for rice and maize as a staple food. However, the 
productivity of the crop in the ENT province is still low ( $\sim \mathrm{t}$ ha-1) as compared to that of the national level $(\sim 17 \mathrm{t}$ ha-1) (BPS Pusat 2020). This low productivity is caused by many factors such as common-yielding variety, poor cropping techniques, drought stress, and also pests and diseases infestations, most specifically the SPW. Developing sweet potato cultivars with the high-yielding ability and good resistance to SPW is a promising approach to tackle the problem. This can be achieved by breeding using the existing and introduced sweet potato germplasm and selecting at the early stages of crop cultivar development. The desirable traits can be introgressed in the earlier generation chosen clones. The incorporated features appear in advanced ages among candidate clones for registration as superior varieties, where SWP resistance is among the unique traits of the candidate variety.

Several purple, orange and yellow-fleshed sweet potato hybrid clones that have been generated and evaluated for yield potential and drought tolerance (Mau et al. 2019) are potential sources of SPW resistance. Evaluation of these clones at an early generation would allow the selection of clones that exhibit the desirable agronomical traits and SPW resistance. Therefore, this study aimed to evaluate the response of yellow and purple-fleshed sweet potato clones to SPW infestation in the laboratory and identify sweet potato clones with good resistance to the weevil.

\section{MATERIALS AND METHODS}

\section{Study site and plant materials}

The study was carried out at the Integrated Field Laboratory of Archipelagic Dryland of Universitas Nusa Cendana, from August to November 2019. Nineteen sweet potato clones were used in the study, consisted of 15 hybrids and four Indonesian released varieties (Table 1). The hybrid clones were produced from crossing between local cultivars and national varieties. The Indonesian released types were provided by the Indonesian Legume and Tuber Research Institute (ILETRI), Malang, East Java.

\section{Experimental design and procedures}

The laboratory experiment was done by an artificial infestation of sweet potato storage roots using adult Cylas formicarius collected from a rearing experiment. The laboratory assays were carried out following Supriyatin and Rahayuningsih (1994) and Zuraida et al. (2005).

The roots of tested sweet potato clones were harvested in the field 18 weeks after planting. The harvested roots were washed under running water and air-dried at room temperature for about one hour. Three fresh roots of about 250-300 g each were put into a plastic container of $4 \mathrm{~L}$ volume covered with a plastic mesh. Each clone consisted of three replicates.

Five pairs of newly emerged sweet potato weevils (SPWs) were introduced into each plastic container and kept at room temperature for five days to allow the female SPW to oviposit. After five days of infestation, the SPW pairs were replaced from the plastic containers. Next, the containers were kept at room temperature for 30 days, after which the roots were taken out from the plastic containers and observed for the research variables.

\section{Observation}

Observed variables included percentage of damaged storage roots, storage root damage intensity, number of weevils (adult + immature) per root, number of feeding tunnels per root, root epidermal thickness, and root latex level.

\section{Percentage of damaged roots}

The tested roots were examined for damage related to SPW feeding, as shown by feeding punctures or feeding cavities in the root surface. Root with damage symptoms was classified as damaged, and that without any damage symptom was considered undamaged by SPW.

The percentage of the damaged root was calculated as:

$$
I=\frac{\mathrm{a}}{\mathrm{a}+\mathrm{b}} \times 100 \%
$$

Where: I: Percentage of the damaged root, a: damaged root, b. undamaged root

Table 1. Sweet potato genotypes evaluated for resistance to sweet potato weevil

\begin{tabular}{|c|c|c|}
\hline Genotype code & Flesh colour & $\begin{array}{c}\text { Origin of } \\
\text { population }\end{array}$ \\
\hline UNC2016.CIL/JPV.01 & Purple & Hybrid Clone \\
\hline UNC2016.CIL/JPV.02 & Light purple & Hybrid Clone \\
\hline UNC2016.CIL/JPV.04 & Light purple & Hybrid Clone \\
\hline UNC2016.CIL/JPV.05 & Purnle & Hybrid Clone \\
\hline UNC2016.KDL/NPL.02 & Purple & Hybrid Clone \\
\hline UNC2016.JPV/KDL.08 & Light orange & Hybrid Clone \\
\hline UNC2016.JPV/KDL.11 & Pale orange & Hybrid Clone \\
\hline UNC2016.JPV/KDL.02 & Light purple & Hybrid Clone \\
\hline UNC2016.NPL/JPV//KDL.02 & Orange & Hybrid Clone \\
\hline UNC2016.KDL/NPL.01 & Orange & Hybrid Clone \\
\hline UNC2016.NPL/PSOL.16 & Purple & Hybrid Clone \\
\hline UNC2016.JPV/KDL/NPL-04-1 & Light purple & Hybrid Clone \\
\hline UNC2016.JPV/KDL/NPL-04-2 & Purple & Hybrid Clone \\
\hline UNC2016.PSOL/NPL-15 & Orange & Hybrid Clone \\
\hline UNC2016.KDL/V1-CIL-01 & Light orange & Hybrid Clone \\
\hline Antin-1 & Purple & ILETRI** \\
\hline Beta-1 & Orange & ILETRI* \\
\hline Beta-2 & Orange & ILETRI* \\
\hline Kidal & Yellow & ILETRI* \\
\hline
\end{tabular}

Note: * Indonesian released variety

Table 2. Percentage and score of root damage intensity (Amalin 1994)

\begin{tabular}{cc}
\hline \% Damage symptom & Damage score \\
\hline$<1 \%$ & 1 \\
$1-25 \%$ & 2 \\
$26-50 \%$ & 3 \\
$51-75 \%$ & 4 \\
$76-100 \%$ & 5 \\
\hline
\end{tabular}


Storage root damage intensity

All roots in the plastic container were observed for root damage intensity. The root was cut lengthwise into two parts of the same size, and the internal damage was observed for the damage intensity. The damage intensity was determined by visually estimated the percent area of damage of the internal root surface and then was given a damage score (Amalin 1994). Roots with $0 \%$ to < $1 \%$ damage intensity were scored 1 , and those exhibiting internal damage of $\geq 1 \%$ were given a score as presented in Table 2. The damage intensity scores were then used to classify the SPW resistance level of the tested genotypes into; Resistant (R) (scores 1.0-< 1.5), Moderately Resistant (MR) (scores 1.5-< 2.5), Moderately Susceptible (MS) (scores 2.5-<3.5) and Susceptible (S) (scores 3.5-5.0).

\section{Number of SPWs (imago + immature) per root}

The number of SPWs per root was observed inside and outside the root within the plastic container. The observation was done after the roots were examined for root damage intensity.

\section{Number offeeding tunnels per root}

The number of feeding tunnels was observed on the root surface, and the average was taken.

\section{Root epidermal thickness}

Freshly harvested roots from the field of about 250-300 $\mathrm{g}$ each were cut crosswise into the same size, and the epidermal thickness was measured. Three replicates were done in each genotype.

\section{Root latex level}

Freshly harvested roots were broken into two by using a knife to allow the flow of the latex. The latex was collected from the broken, exposed surface with a tube. The amount of latex was then classified into low, medium, and high.

\section{Data analysis}

Arcsine transformed the percentage of damaged root and root damage intensity data. Those of the total SPWs and the number of tunnels per root were changed by square root +0.5 before ANOVA. Root epidermal thickness was subjected to ANOVA without transformation. Variables significantly affected by the treatments were subjected to post hoc Duncan Multiple Range Test (DMRT) at the 5\% significant level to see the difference between the treatment means. The root damage intensity score data was used to group the SPW resistance level of tested sweet potato clones. Root latex production was subjected to descriptive analysis. Correlation analysis was carried out to see the relationship between the observed variables.

\section{RESULTS AND DISCUSSION}

Percentage of damaged root and root damage intensity

Fresh roots harvested from the field experiment were used for the laboratory assay. After one month of SPW infestation, the roots were examined for the percentage of the damaged roots and the intensity of root damage, as presented in Table 3 .

Table 3. Means of the percentage of the damaged root, root damage intensity, root damage score, and SPW resistance level of tested sweet potato genotypes

\begin{tabular}{|c|c|c|c|c|}
\hline Sweet potato genotype/code & Damaged root $(\%)$ & Root damage intensity (\%) & $\begin{array}{l}\text { Root damage } \\
\text { score }\end{array}$ & $\begin{array}{c}\text { SPW resistance } \\
\text { level } *\end{array}$ \\
\hline UNC2016.CIL/JPV-01 & $88.89^{a}$ & 46.72 cde & 3.10 & MS \\
\hline UNC2016.CIL/JPV-02 & $100.00^{b}$ & 54.84 cdef & 3.05 & MS \\
\hline UNC2016.CIL/JPV-04 & $100.00^{b}$ & $14.09^{\mathrm{a}}$ & 2.08 & MR \\
\hline UNC2016.CIL/JPV-05 & $88.89^{\text {b }}$ & $13.95^{\mathrm{a}}$ & 1.77 & MR \\
\hline UNC2016.KDL/NPL-02 & 77.78 a & $39.60^{\mathrm{cd}}$ & 3.03 & MS \\
\hline UNC2016.JPV/KDL-08 & $88.89^{\text {b }}$ & 65.33 defg & 3.94 & $\mathrm{~S}$ \\
\hline UNC2016.JPV/KDL-11 & $88.89^{\mathrm{b}}$ & 47.08 cde & 3.07 & MS \\
\hline UNC2016.JPV/KDL-02 & $77.78^{a}$ & 41.10 cde & 2.89 & MS \\
\hline UNC2016.NPL/JPV/KDL-02 & $77.78^{a}$ & 50.06 cde & 3.23 & MS \\
\hline UNC2016.KDL/NPL-01 & $100.00^{b}$ & $76.60 \mathrm{~g}$ & 3.72 & $\mathrm{~S}$ \\
\hline UNC2016.NPL/PSOL-16 & $88.89^{\text {b }}$ & 72.17 efg & 3.53 & $\mathrm{~S}$ \\
\hline UNC2016.JPV/KDL/NPL-04-1 & $100.00^{\mathrm{a}}$ & 41.90 cde & 2.65 & MS \\
\hline UNC2016.JPV/KDL/NPL-04-2 & $100.00^{\text {a }}$ & 51.23 cde & 3.04 & MS \\
\hline UNC2016.PSOL/NPL-15 & $100.00^{\mathrm{a}}$ & 52.92 cde & 3.06 & MS \\
\hline UNC2016.KDL/V1-CIL-01 & 88.89 b & $32.62 \mathrm{bc}$ & 2.60 & MS \\
\hline Antin-1 & 88.89 b & $67.46 \mathrm{fg}$ & 3.95 & $\mathrm{~S}$ \\
\hline Beta-1 & $66.67^{a}$ & 41.69 cde & 2.55 & MS \\
\hline Beta-2 & $66.67^{a}$ & $19.27 \mathrm{ab}$ & 2.18 & MR \\
\hline Kidal & $100.00^{\mathrm{a}}$ & $11.37^{\mathrm{a}}$ & 1.72 & MR \\
\hline Coefficient of Variation $(\%)$ & 14.40 & 13.37 & & \\
\hline Standard Error & 2.69 & 2.90 & & \\
\hline
\end{tabular}

Note: Different superscripts letters within the same column denotes significant difference (DMRT 0.05) among means. MR: Moderately Resistant, MS: Moderately Susceptible, S: Susceptible. *Resistance level was determined based on Score of Root Damage Intensity (Amalain 1994) 
Table 3 reveals that most tested SPW damaged sweet potato clones, ranging from $66.7-100 \%$ of the evaluated roots. For example, about $66.7 \%$ of storage roots of the check varieties Beta-1 and Beta-2 were damaged by SPW, while three hybrid clones (UNC2016.KDL/NPL-2, UNC2016.JPV/KDL-2, and UNC2016.NPL/JPV/KDL-2) had $77.8 \%$ of their storage roots been damaged by SPW. The remaining sweet potato clones had $88.9-100 \%$ of their roots damaged by the SPW.

The percentage of the damaged root as described above was determined based on SPW damage on the surface of tested roots, regardless of the damage intensity. In contrast, the root damage intensity was determined based on visual observation of internal root damage described in Table 3. The root damage intensity of the evaluated sweet potato clones varied significantly, ranging from $11.4 \%$ to $76.6 \%$. Table 3 shows that 10 of the tested clones suffered root damage intensity of less than $50 \%$, while the rest nine clones had more than $50 \%$ root damage intensity. Sweetpotato genotypes suffering the least $(<20 \%$ root damage intensity) included the check varieties Kidal and Beta-2 and the hybrid clones UNC2016.CIL/JPV-4 and UNC2016.CIL/JPV-5. While the highest root damage intensity was observed in the hybrid clone UNC2016.KDL/NPL-1, which was not significantly different from that of Antin 1, UNC2016.NPL/PSOL-16, and UNC2016.JPV/KDL-8. These data presumably indicate varying resistance levels of the tested sweet potato clones against $C$. formicarius.

\section{Storage root damage score and SPW resistance level}

The storage root damage intensity was assigned with root damage scores before the SPW resistance level of the tested sweet potato genotypes. The root damage intensity was scored 1 to 5 (Amalin 1994; Mau et al. 2011) as presented in Table 3 and used to classify the resistance level of the tested clones. The damage scores ranged from 1.72 to 3.72 , which organized the tested clones into three categories, i.e., moderately resistant (MR), moderately susceptible (MS), and Susceptible (S). Only two hybrid clones (UNC2016.CIL/JPV-4 and UNC2016.CIL/JPV-5) were relatively resistant to SPW, while the remaining hybrid clones were either moderately susceptible or susceptible to SPW. Meanwhile, of the four check varieties, Beta-2 and Kidal were relatively resistant and the remaining two checks, i.e., Beta-1 and Antin-1, were moderately susceptible and susceptible, respectively. Thus, none of the 17 tested clones was resistant to SPW.

\section{Number of SPWs and feeding tunnels, root epidermal thickness, and root latex level}

In addition to the percentage of damaged root and root damage intensity, other variables assumed to be correlated with these two variables were also observed. These included the number of SPWs per root, number of feeding tunnels per root, root epidermal thickness, and root latex level. Data of these variables are presented in Table 4.

The results demonstrated that the number of SPWs varied significantly among the tested sweet potato clones. The highest number of SPWs (31.9) was observed on UNC2016.JPV/KDL-11 while the lowest (1.4) was observed in UNC2016.CIL/JPV-04. One-half of tested sweet potato clones had more than $10 \mathrm{SPW}$ per root during 30 days of infestation.

Table 4. Means of number of sweet potato weevils (SPWs) per root, number of feeding tunnels per root, root epidermal thickness, and root latex level

\begin{tabular}{|c|c|c|c|c|}
\hline Sweet potato genotype/code & $\begin{array}{c}\text { Number of SPWs per } \\
\text { root }\end{array}$ & $\begin{array}{l}\text { Number of feeding tunnels } \\
\text { per root }\end{array}$ & $\begin{array}{l}\text { Root epidermal } \\
\text { thickness }(\mathbf{m m})\end{array}$ & $\begin{array}{c}\text { Root } \\
\text { latex level }\end{array}$ \\
\hline UNC2016.CIL/JPV-01 & $4.9^{\mathrm{cd}}$ & $4.61^{\mathrm{cd}}$ & $2.49^{b c}$ & + \\
\hline UNC2016.CIL/JPV-02 & $2.8 \mathrm{bc}$ & $2.93 \mathrm{abc}$ & $2.83^{\mathrm{cd}}$ & ++ \\
\hline UNC2016.CIL/JPV-04 & $1.4^{\mathrm{a}}$ & $1.36^{\mathrm{a}}$ & $2.00^{\mathrm{b}}$ & + \\
\hline UNC2016.CIL/JPV-05 & $2.9 \mathrm{bc}$ & $2.76^{a b c}$ & $1.08^{\mathrm{a}}$ & + \\
\hline UNC2016.KDL/NPL-02 & $3.8 \mathrm{bc}$ & $3.72 \mathrm{bc}$ & $3.00^{\mathrm{cd}}$ & ++ \\
\hline UNC2016.JPV/KDL-08 & $27.3^{\mathrm{h}}$ & $26.83^{\mathrm{i}}$ & $2.83^{\mathrm{cd}}$ & ++ \\
\hline UNC2016.JPV/KDL-11 & $31.9^{\mathrm{h}}$ & $31.11^{\mathrm{i}}$ & $4.00^{\mathrm{f}}$ & + \\
\hline UNC2016.JPV/KDL-02 & $15.0^{\mathrm{fg}}$ & $15.65 \mathrm{fgh}$ & $2.00^{\mathrm{b}}$ & + \\
\hline UNC2016.NPL/JPV/KDL-02 & $7.8 \mathrm{de}$ & $8.03 \mathrm{de}$ & 3.67 ef & ++ \\
\hline UNC2016.KDL/NPL-01 & $17.2 \mathrm{~g}$ & $16.94^{\mathrm{h}}$ & $3.00^{\mathrm{cd}}$ & ++ \\
\hline UNC2016.NPL/PSOL-16 & $15.8^{\mathrm{g}}$ & $16.03 \mathrm{gh}$ & $2.83^{\mathrm{cd}}$ & + \\
\hline UNC2016.JPV/KDL/NPL-04-1 & $1.8 \mathrm{~b}$ & $2.07 \mathrm{ab}$ & $1.92 \mathrm{~b}$ & ++ \\
\hline UNC2016.JPV/KDL/NPL-04-2 & $13.1 \mathrm{fg}$ & 13.34 fgh & $2.83^{\mathrm{cd}}$ & ++ \\
\hline UNC2016.PSOL/NPL-15 & $6.4^{\mathrm{d}}$ & $6.31^{\mathrm{d}}$ & $2.17^{\mathrm{b}}$ & ++ \\
\hline UNC2016.KDL/V1-CIL-01 & $12.3 \mathrm{fg}$ & $12.17 \mathrm{fg}$ & 3.33 de & + \\
\hline Antin-1 & 10.9 ef & 10.76 ef & $3.00 \mathrm{~cd}$ & + \\
\hline Beta-1 & $13.8 \mathrm{fg}$ & $13.22 \mathrm{fgh}$ & $3.00 \mathrm{~cd}$ & +++ \\
\hline Beta-2 & $1.7 \mathrm{ab}$ & 12.57 a & $2.87^{\mathrm{cd}}$ & ++ \\
\hline Kidal & $2.4^{\mathrm{b}}$ & $2.51 \mathrm{abc}$ & $3.10^{\text {cde }}$ & ++ \\
\hline Coefficient of Variation $(\%)$ & 8.91 & 9.91 & 10.15 & \\
\hline Standard Error & 0.29 & 0.29 & 0.15 & \\
\hline
\end{tabular}

Note: Different superscripts letters within the same column denotes significant difference (DMRT 0.05) among means. ${ }^{+}$Low, ${ }^{++}$Medium, and ${ }^{+++}$High 
Table 5. Correlation between observed variables of tested sweet potato genotypes

\begin{tabular}{lccccc}
\hline Observed variables & $\begin{array}{c}\text { Percentage of } \\
\text { damaged root }\end{array}$ & $\begin{array}{c}\text { Root damage } \\
\text { intensity }\end{array}$ & $\begin{array}{c}\text { Number of SPWs } \\
\text { per root }\end{array}$ & $\begin{array}{c}\text { Number of feeding } \\
\text { tunnels per root }\end{array}$ & $\begin{array}{c}\text { Root epidermal } \\
\text { thickness }\end{array}$ \\
\hline Percentage of damaged root & & 0.56 & 0.75 & 0.36 & 0.39 \\
Root damage intensity & $0.14^{\mathrm{ns}}$ & & 0.02 & 0.04 & 0.17 \\
Number of SPW per root & $-0.08^{\mathrm{ns}}$ & $0.54^{*}$ & & 0.00 & 0.04 \\
Number feeding tunnels per root & $-0.22^{\mathrm{ns}}$ & $0.47^{*}$ & $0.96^{* *}$ & & 0.03 \\
Root epidermal thickness & $-0.21^{\mathrm{ns}}$ & $0.33^{\mathrm{ns}}$ & $0.48^{*}$ & $0.50^{*}$ & \\
\hline N & & & & \\
\hline
\end{tabular}

Note: Numbers below the dashed-box diagonal are Pearson's correlation coefficient values, and those above the diagonal are the p-

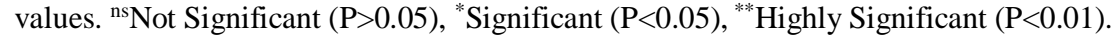

The number of feeding tunnels per root also differed significantly among the clones. Generally, roots with lower SPW numbers also had fewer feeding tunnels per root and vice versa (Table 4). The number of SPWs also corresponded strongly with the number of feeding tunnels per root. This indicates a strong correlation between the two variables.

Root epidermal thickness also varied among the tested clones, ranging from $1.08 \mathrm{~mm}$ to $4.0 \mathrm{~mm}$. Eight of the tested clones had root epidermal thickness between 3.0-4.0 $\mathrm{mm}$, while the rest had $<3 \mathrm{~mm}$ epidermal thickness. The root epidermal thickness seems to be corresponding well with either number of SPWs or the number of feeding tunnels per root, indicating a significant correlation among them. The qualitative assessment also showed that roots of the tested sweet potato clones produced varying levels of latex, ranging from low to high levels (Table 4).

\section{Correlations among observed variables}

The observed variables were subjected to correlation analysis to reveal their association. The results (Table 5) showed a differential correlational pattern among variables. The percentage of damaged roots was not correlated with other observed variables. At the same time, root damage intensity was positively correlated with the number of SPWs per root $(r=0.54)$ and the number of feeding tunnels per root $(r=0.47)$. Furthermore, a highly significant and positive correlation $(r=96)$ was observed between the number of SPW per root and the number of feeding tunnels per root $(r=0.96)$. The results also showed that root epidermal thickness had a positive and moderate correlation with either number of SPW per root $(r=0.48)$ or the number of feeding tunnels per root $(\mathrm{r}=0.50)$.

\section{Discussion}

The present study results revealed variable responses of sweet potato genotypes against SPW. Both the percentage of damaged root and root damage intensity differed significantly among the tested sweet potato genotypes. Most of the roots of the sweet potato genotypes were damaged by SPW as in the present no choice bioassay. The weevils were forced to feed on the roots for their survival and also for oviposition. For completing their life cycle, the weevils cause feeding destruction to sweet potato roots, vines, stems, and leaves (Kyereko et al. 2019). In roots, after mating, the female weevils create feeding punctures on the roots to lay eggs (Matthews 2002; Muyinza 2010), and the developing larvae will make tunnels in holes inside the roots, feed and develop into adults within the roots.

Both the percentage of damaged roots and root damage intensity in this study $(77.8-100 \%$ and $14.0-76.6 \%$, respectively) differed in range as compared to those of the previous research by Mau et al. (2011) (24.1-88.3 and 3.8$67.9 \%$, respectively) on local and released sweet potato genotypes from Indonesia. These differences may have been caused by differences in genotypes being tested and the sweet potato root production sites. This is supported by the findings of Jackson et al. (2012), who also found different percentages of damaged roots among plant introduction (PI) sweet potato accessions on multi-year and multi-site experiments. In addition, the effect of genotype by location on the percentage of SPW damage on sweet potato genotypes has also been reported by Mao et al. (2001).

Consistent with the percentage of damaged root and root damage intensity, the root damage score, and hence, the resistant level of tested sweet potato genotypes also significantly differed among tested sweet potato clones. Of the 19 genotypes tested, none was found to be resistant to SPW. Only four clones were moderately resistant, and the rest of the genotypes were moderately susceptible and susceptible to SPW. This finding confirmed previous study results (Zuraida et al. 2005; Mau et al. 2011), where SPW resistant genotypes were hardly encountered. Zuraida et al. (2005) identified only one SPW resistant clone out of 50 genotypes tested, while Mau et al. (2011) found only one out of 10 tested clones to be resistant to SPW. In addition, using a bionomic of the sweet potato weevil, Adom et al. (2018) identified one out of four sweet potato genotypes tested to be less susceptible to $C$. puncticollis.

Rais et al. (2004) identified 10 SPW resistant sweet potato genotypes out of 70 accessions tested. Further, Jackson et al. (2012) identified several SPW resistant genotypes out of 55 sweet potato PI accessions. All these findings imply that the success of finding sweet potato genotypes with good SPW resistance is very much dependent on the genetic background of the germplasm evaluated, and is to some extent, on the effect of planting environments that influence the nutritional quality of sweet potato storage root that influence the preference of SPW (Parr et al. 2016).

The present study classified the tested sweetpotato genotypes into three categories of resistance level, i.e., moderately resistant (four genotypes), moderately 
susceptible (11 genotypes) and susceptible (four genotypes). The mechanism of resistance was not elucidated in detail in the present study. Still, the observed variables related to SPWs and the root morphology may provide insights into the resistance mechanism in the studied genotypes.

In addition to the percentage of damaged root and root damage intensity, SPW per root, number of feeding tunnels per root, root epidermal thickness, and root latex level also varied among tested sweet potato genotypes. Differences in the number of SPWs and number of feeding tunnels per root may imply differences in SPW preference toward the sweet potato genotypes, which determine the oviposition preference that in turn determines the number of eggs laid, and hence the number of the following growth stages such as larvae, pupae and imago (Kyereko et al. 2019). The SPWs will determine the number of feeding tunnels created as shown by a highly significant and positive correlation between the two variables $(r=0.96)$. Correlation analysis results also revealed that root damage intensity was positively and significantly correlated with the number of SPWs and the number of feeding tunnels per root. The positive correlation indicates that an increase in the number of SPWs and, hence the number of feeding tunnels per root will also be accompanied by an increase in root damage intensity as the higher the number of SPWs, the more the requirement for food. Thus, the root will be damaged for food provision. A similar result of a highly significant and positive correlation between root damage intensity and the number of SPWs was also observed by Mau et al. (2011) on Indonesian local and released sweet potato varieties. These results imply that the tested genotypes possess different resistance mechanisms against the SPW.

A moderately positive correlation was observed between root epidermal thickness with either number of SPWs $(r=0.48)$ and the number of feeding tunnels $(r=$ 0.50 ), indicating that the thicker the root epidermis, the higher the number of SPWs and number of feeding tunnels per root. However, the association of the root epidermal thickness with the two variables is biologically unexplainable in this study. It contradicts Korada et al. (2010) statement that epidermal thickness could affect cultivar preference by inhibiting the SPW mouthpart penetration. This, in turn, will affect the feeding site decision of SPW. Alternatively, the observed association between epidermal thickness and the number of SPWs found in this study could have randomly occurred and not related to the SPW resistance mechanism. Further, Mau et al. (2011) observed no correlation between root epidermal thickness with either number of SPWs or the number of feeding tunnels per root.

The tested sweet potato genotypes also differed in latex production level. Although the latex production was assessed qualitatively, the observed data seems not strongly associated with resistance level as two of the moderately resistant (MR) genotypes produced only a low latex level. In contrast, the other two MR genotypes had a moderate latex level. On the contrary, a high latex production level was observed on a moderately susceptible (MS) genotype (Table 4). Thus, the latex production levels observed in the present study seem unrelated to SPW resistance. This finding contrasts the previous reports (Data et al. 1996; Stevenson et al. 2009; Rukarwa et al. 2013; Anyanga 2015), who found that chemical differences in periderm and epidermal latex could mediate resistance to SPW. The chemical compounds in root surface, periderm, and epidermal latex that may mediate resistance include hydroxycinnamic acid esters such as hexadeyl caffeic acid, heptadecyl caffeic acid, octadecyl caffeic acid, and octadecyl coumaric acid (Harrison et al. 2003; Muyinza 2010; Anyanga et al. 2013; Anyanga 2015).

Overall, the present study results revealed a variable SPW resistance among the tested sweet potato genotypes; four genotypes were moderately resistant (MR). The remaining 15 genotypes were either moderately susceptible or susceptible to SPW. The MR genotypes included twohybrid purple-fleshed clones, i.e., UNC2016.CIL/JPV-04, UNC2016.CIL/JPV-05 and two released varieties, i.e., Beta 2 and Kidal. Kidal has also been moderately resistant to SPW in the previous study (Mau et al. 2011), thus, expressing its actual resistance instead of being an escape. Therefore, the SPW-MR genotypes are potential sources for developing sweet potato superior varieties with high SPW resistance. The hybrid clone UNC2016.CIL/JPV-05 has also been recorded to have a high yield ( $23 \mathrm{t}$ ha-1) in the previous study (Mau et. 2019). Thus it is promising for varietal release.

\section{ACKNOWLEDGEMENTS}

We are very thankful to the Directorate of Research and Community Services (DRPM) of the Indonesian Ministry of Research, Technology and Higher Education for supporting this research through Penelitian Terapan research scheme, the financial year 2019. Special thanks are also addressed to Teroci Lake for providing the selected roots from the field.

\section{REFERENCES}

Adom M, Wilson DD, Fening KO, Bruce AY, Adofo K. 2018. Bionomics of the sweet potato weevil, Cylas puncticollis (Coleoptera: Brentidae) on four different sweet potato varieties in sub-Saharan Africa. J Agric Rural Dev Trop Subtrop 119(1): 55-63.

Alcazar J, Cisneros F, Morales A. 1997. Large-Scale Implementation of IPM for Sweet potato Weevil in Cuba: A Collaborative Effort. Working Paper. CIP.

Amalin DM. 1994. Arthropod pest damage evaluation in relation to varietal resistance evaluation in sweet potato. In: Rasco JET, Amante VDR (eds). Sweet Potato Variety Evaluation. SAPPRAD 1: 56-59.

Anyanga MO, Muyinsa H, Talwana H, Hall DR, Farman DI, Semakula GN, Mwange ROM, Stevenson PC. 2013. Resistance to the weevils Cylas puncticollis and Cylas brunneus by sweet potato root surface compounds. J Agric Food Chem 61(34): 8141-8147. DOI: 10.1021/jf4024992.

Anyanga MO. 2015. Phytochemical Mediated Resistance in Sweet Potato Weevils. [Thesis]. University of Greenwich, London.

BPS NTT. 2020. Harvest Area, Average Production, and Productivity of Sweet potato, 2009-2019. Central Bureau of Statistics of Nusa Tenggara Timur Province, Kupang, NTT. [Indonesian]

BPS Pusat. 2020. Statistics of Indonesia. Indonesian Central Bureau of Statistics, Jakarta. [Indonesian] 
Chalfant RB, Jansson RK, Seal DR, Schalk JM. 1990. Ecology and management of sweet potato insects. Annu Rev Entomol 35(1): $157-$ 180. DOI: 10.1146/annurev.en.35.010190.001105.

Chen J. 2017. Evaluation of control tactics for management of sweet potato weevil (Coleoptera: Curculionidae). LSU Doctora Dissertations. 4401. Avauable from: https://digitalcommons.lsu.edu/gradschool_dissertations/4401

Data ES, Nottingham SF, Kays SJ. 1996. Effect of sweet potato latex on sweet potato weevil feeding and oviposition. J Econ Entomol 89: 544549. DOI: $10.1093 /$ jee/89.2.544.

Harrison HF Jr, Peterson JK, Snook ME, Bohac JR, Jackson DM. 2003. Quality and potential biological activity of cafeic acid in sweet potato (Ipomoea batatas (L) Lam) storage root periderm. J Agric Food Chem 51: 2943-48. DOI: 10.1021/jf0211229.

Jackson DM, Harrison HD, Ryan-Bohac JR. 2012. Insect resistance in sweet potato plant introduction accessions. J Econ Entomol 105(2): 651-658. DOI: 10.1603/EC11307.

Jansson RK, Bryan HH, Sorensen KA. 1987. Within-vine distribution and damage of sweet potato weevil, Cylas formicarius elegantulus (Coleoptera: Curculionidae), on four cultivars of sweet potato in Southern Florida. Fla Entomol 70(4): 523-526. DOI: $10.2307 / 3494797$.

Korada RR, Naskar SK, Palaniswami MS, Ray RC. 2010. Management of sweetpotato weevil [Cylas formicarius (Fab.)]: an overview. J Root Crops 36:14-26.

Mao L, Jett LE, Story RN, Hammond AM, Labonte DR. 2001. Effect of sweet potato genotype, storage time, and production site on feeding and oviposition behaviour of the sweet potato weevil, Cylas formicarius (Coleoptera: Apinidae). Fla Entomol 84(2): 259-264. DOI: $10.2307 / 3496177$.

Kyereko WT, Hongbo Z, Amoanimaa-Dede H, Meiwei G, Yeboah A 2019). The major sweet potato weevils; Management and control: A review. Entomol Ornithol Herpetol 8: 218. DOI: 10.35248/21610983.8.218.

Matthews G. 2002. Handbook of vegetable pests. Crop Prot 21:431. DOI: 10.1016/S0261-2194(01)00092-8.

Mau YS, Ndiwa ASS, Arsa IGBA. 2011. Resistance level of several sweet potato clones from East Nusa Tenggara against lanas pests (Cylas formicarius Fab.). Jurnal Hama dan Penyakit Tumbuhan Tropik 11(2): 139-146. DOI: 10.23960/j.hptt.211139-146. [Indonesian]
Mau YS, Ndiwa ASS, Markus JER, Arsa IGBA. 2019. Agronomic performance and drought tolerance level of sweet potato hybrids grown in Kupang, East Nusa Tenggara, Indonesia. Biodiversitas 20(8): 2187-2196. DOI: 10.13057/biodiv/d200812.

Muyinza H. 2010. Components of Resistance to the Sweet Potato Weevils Cylas puncticollis (Coleptera: Apoindae) I Ugandan Sweet Potato Germplasm. [Thesis]. Makerere University, Kampala.

Nderitu J, Silai M, Nyamasyo G, Kasina M. 2009. Insect species associated with sweet potatoes (Ipomoea batatas (L.) Lam.) in eastern Kenya. Int J Sustain Crop Prod 4(1): 14-18.

Parr MC, Ntonifor NN, Jackai LEN. 2016. Evaluation of sweet potato cultivars for differences in Cylas puncticollis (Curculionidae: Brentidae) damage in South Western Cameroon. Int J Agric Sci (IJRAS) 3(1): 1-8

Rais SA, Silitonga TS, Budiarti SG, Zuraida N, Sudjadi M. 2004. Evaluation of Germplasm Resistance of Food Crops to Stress of Several Biotic Factors (Pests and Diseases). Minutes of Seminar on Pioneering Research and Plant Biotechnology. Balai Besar-Biogen, Bogor. [Indonesian]

Rukarwa RJ, Prentice K, Ormachea M, Kreuze JF, Tovar J, Mukasa SB et al. 2013. Evaluation of bioassays for testing Bt sweet potato events against sweet potato weevils. African Crop Sci J 21(3):235-244.

Smith T, Beuzelin J. 2015. Insect Pest Management in Louisiana Sweet potatoes. Louisiana State University Agricultural Center. Publication No.2620.

Stevenson PC, Muyinza H, Hal DR, Porter EA, Farman D, Talwana H, Mwanga ROM. 2009. Chemical basis for resistance in sweet potato Ipomoea batatas to the sweet potato weevil Cylas puncticollis. Pure Appl Chem 81(1): 141-151. DOI: 10.1351/PAC-CON-08-02-10.

Supriyatin, Rahayuningsih A. 1994. Evaluation of the resistance of sweet potato clones to Boleng pest (Cylas formicarius F.). Edisi Khusus Balittan Malang 3: 211-215. [Indonesian]

Talekar NS. 1982. Effects of a sweet potato weevil (Coleoptera: Curculionidae) infestation on sweet potato root yields. J Econ Entomol 75(6): 1042-1044. DOI: 10.1093/jee/75.6.1042.

Zuraida N, Minantyorini, Koswanudin D. 2005. Screening of sweet potato germplasm resistance against lanas pests. Buletin Plasma Nutfah 11(1): 11-15. [Indonesian] 